\section{Corrigendum to: Nano-Surface Implants: Indications and Limitations}

Moustapha Hamdi, MD, PhD
Aesthetic Surgery Journal 2021, Vol 41(10) NP1353 (C) The Author(s) 2021. Published by $O x f o r d$ University Press on behalf of The Aesthetic Society. All rights reserved. For permissions, please e-mail: journals.permissions@oup.com DOI: 10.1093/asj/sjab256

www.destheticsurgeryjournal.com
In the article "Nano-Surface Implants: Indications and Limitations" by Hamdi in Aesthet Surg J, sjaa265, https:// doi.org/10.1093/asj/sjaa265, the following disclosures were omitted and outlined here for transparency.

Dr Hamdi served as a consultant for Polytech (Dieburg, Germany), Orbishape (Orbix Medical, Tel Aviv, Israel), and Zeiss (Oberkochen, Germany). Polytech was one of many sponsors of the CATBBAS meeting, for which Dr Hamdi serves as Program Director and Congress Organizer. Dr Hamdi received travel expenses from Polytech for educational presentations at some meetings but not for the 2nd World Conference on BIA-ALCL in November 2020 in Houston, Texas. Polytech provides a grant for the Brussels Breast Fellowship including the inscription to the European Master's degree in surgical oncology, reconstructive and aesthetic surgery, issued by Barcelona University, Barcelona, Spain, for which Dr Hamdi serves as the Chairman of the Scientific Committee. The author regrets these oversights.

These errors have been corrected online. 